\title{
Perceived Causes of Infertility: Accounts of Infertile Individuals in Kwara South, Nigeria
}

\author{
Iwelumor Oluwakemi $\mathbf{S}^{1}$, Shariffah Suraya Syed Jamaludin ${ }^{2}$, Babatunde Seun $\mathrm{K}^{3}$ \\ ${ }^{1}$ Doctoral Candidate: Anthropology and Sociology Section, ${ }^{2}$ Senior Lecturer: Anthropology and Sociology \\ Section, School of Social Sciences, Universiti Sains Malaysia, Malaysia, ${ }^{3}$ Independent Researcher, Staff Quarters, \\ Landmark University, Omu-Aran, Kwara State, Nigeria
}

\begin{abstract}
Infertility is perceived differently across socio-cultural contexts and studies have shown these perceptions affect the overall management of infertility. This study specifically explored the perceived causes of infertility among infertile married persons experiencing primary infertility in Kwara South, Nigeria. The study adopted a qualitative design. Infertile persons were recruited through snowball sampling technique. Data was collected through semi-structured in-depth interviews of 12 infertile married women and 7 infertile men. The data were analyzed using conventional content analysis with the aid of Atlas.ti 7. Findings showed that infertility is defined as barrenness and childlessness. Sociocultural factors rather than biomedical factors were exalted as primary causes of infertility. These include lifestyle choices or habits, rape, spiritual oppression, witchcraft/sorcery, trial and punishment from God. Understanding these perceptions will enhance the development of culture-specific programs targeted at managing infertility in Nigeria.
\end{abstract}

Keywords: Infertility; Childlessness; Sociocultural perception; Perceived cause; Nigeria.

\section{Introduction}

There is no gainsaying the fact that infertility is both a social and medical problem. Infertility literally connotes a condition of childlessness or a failure to achieve desired pregnancy and/or live-birth. Most studies on infertility in developing nations have focused on the prevalence and biomedical cause of infertility with a view to improving service delivery on treatments and assessment for psychological counseling. While a few have examined public perceptions on the meaning of infertility, empirical examples are scarce of how infertile persons perceive the cause of their situation.

This study explored how married women and men experiencing primary infertility in Kwara South, Nigeria perceives the cause of their situation. This is significant because it provides an avenue to better understand the social causes of infertility as perceived by infertile

\footnotetext{
Corresponding Author** Iwelumor Oluwakemi S

Anthropology and Sociology Section, School of Social Sciences, Universiti Sains Malaysia, Malaysia e-mail: babatundeshade.k@gmail.com
}

persons rather than have the perceptions of others imposed on them. This would also go a long way to mitigating some of the discriminatory practices against married infertile persons in Nigeria.

Literature Review: Revealing the cause of infertility in developing nations relies on orthodox healthcare and ethnogynecology ${ }^{1}$. Several studies in sub-Saharan Africa have shown that sexually transmitted infections and genital tract infections are the primary causes of male and female infertility ${ }^{2-5}$. Though many affirm this, sexual promiscuity is believed to be the significant causal factor, rather than those infections since the latter is understood to be prevalent among the morally decadent in the society ${ }^{6-8}$.

Sequel to promiscuity, abortion is also culturally perceived in Nigeria as a leading cause of infertility among women. This is premised on the belief that promiscuity increases the chance of one having unwanted pregnancies which often lead to unsafe abortions with severe outcomes. Complications from abortions have been linked to procedures and objects some women use to induce abortion which includes solvent, detergent, alcohol, decoctions inserted into the vagina and other traditional herbs 9,10 . 
Similarly, contraceptives are also thought to cause infertility. While some are believed to be outrightly linked to infertility, overuses of others are thought to disrupt natural functions of the body eventually leading to infertility. This is culturally tied to the belief in predestination. Yoruba people believe that everyone comes to the earth with a definite number of offspring which can be expended through abortions and contraceptive use. Such people can become infertile when they eventually resolve to have children ${ }^{6,11}$.

The belief in supernatural bases of infertility has different dimensions. Firstly, children are believed to be gifts from God and he gives to whomever he wills and at different times. Thus, while many infertile couples live in denial of their conditions with a hope that they will eventually have children, others see infertility as temporary trial or persecution that will be overcome. Secondly, infertility has been attributed to God's wrath or punishment from ancestors or deities for violation of cultural norms or wicked acts $6,12,13$.

Another dimension is the link between witchcraft inflicted by the wicked in the community and that curses can be placed on individuals or couples to be childless through spiritual powers and evil spirits. Some infertile women are also believed to be witches, who have vowed not to have children by not becoming pregnant, 'devouring' the fetus in utero or at birth ${ }^{6,14}$.

Methodology: A qualitative exploratory research design was adopted to explore the perceived sociocultural cause of infertility among married infertile persons. The study population consisted of twelve (12) women and seven (7) men experiencing primary infertility, at least two years prior to this study from Kwara South Nigeria. Participants were recruited through snowball sampling technique with the assistance of two (2) gatekeepers. The research instrument was a semi-structured in-depth interview, using an open-ended interview question guide. All interviews were recorded with the approval of participants and ranged from 50 to 110 minutes.

Interviews were done at places chosen by research participants and in their preferred languages. The data were transcribed, arranged in codes, and examined for categories and themes using conventional content analyses with the aid of ATLAS.ti (version 7). Qualitative content analysis was done based on the evaluation criteria suggested by Lincoln and Guba 15. The University of Ilorin Teaching Hospital Ethical Review Committee gave ethical clearance for the study. All selected research participants gave written informed consent.

\section{Results and Findings}

Characteristics of study participants: Infertility from this study is broadly defined as a lack of conception and/or inability to bear a child further described as barrenness and childlessness respectively. All the participants in this study were grappling with primary infertility which studies have shown have greater consequences than secondary infertility ${ }^{16-18}$. They differ remarkably in age, sex, duration of infertilityWrittenand religion. Their ages ranged between $24-52$ years, majority of them were women (12 participants), and the duration of infertility was between $3-22$ years while the bulk of them (17 participants) were Christians.

Also, a good number of the participants were educated as eleven had university degrees or its equivalent, four had postgraduate degrees and the least educated (two participants) had basic Senior Secondary School Certificates. This affirms the findings of some studies that the prevalence of infertility rises with age and primary infertility could be higher among more educated women ${ }^{17,19,20}$. Table 4.1 shows the characteristics of the participants. 
Table 1: Information on Study Participants

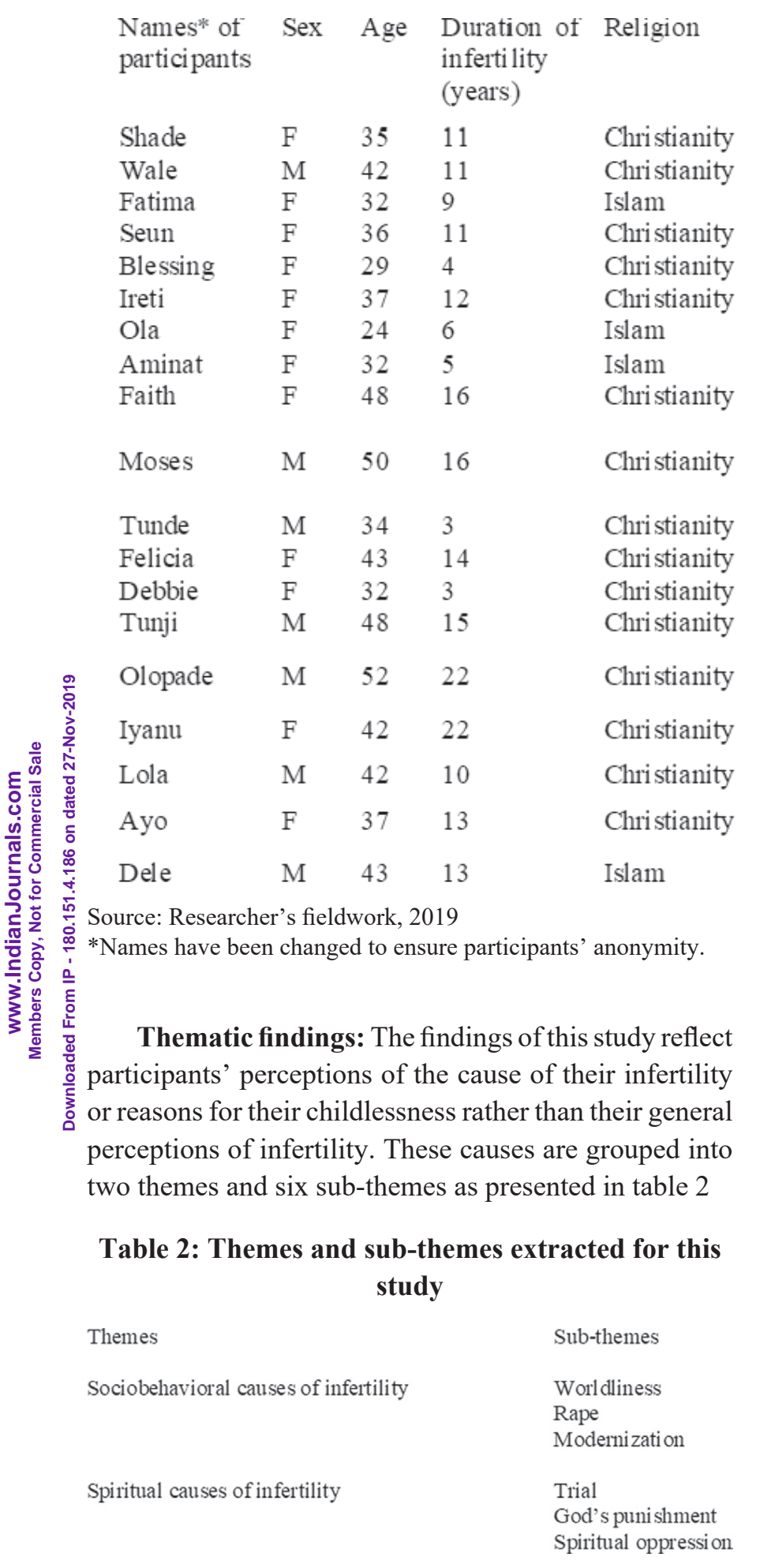

Education Occupation

(1)

HND

BEng

B Sc

B.Ed.

B.Ed.

HND

SSCE

MBA

$\mathrm{BSC}$

$\mathrm{MSc}$

SSCE

$\mathrm{BSC}$

$\mathrm{NCE}$

MSc

$\mathrm{NCE}$

B.ED

B.ED

$\mathrm{BSC}$

MBA

$\begin{array}{lll}\text { Housewife } & - & \text { Monogamous } \\ \text { Contractor } & 200000 & \text { Monogamous } \\ \text { Business } & 100000 & \text { Polygamous } \\ \text { Teacher } & 45000 & \text { Polygamous } \\ \text { Housewife } & 5000 & \text { Monogamous } \\ \text { Civil Servant } & 76000 & \text { Monogamous } \\ \text { Business } & 50000 & \text { Extended } \\ \text { Civil Servant } & 100000 & \text { Monogamous } \\ \text { Public } & 160000 & \text { Monogamous } \\ \text { Servant } & & \\ \text { Security } & 150000 & \text { Monogamous } \\ \text { Expert } & & \\ \text { Artisan } & 20000 & \text { Monogamous } \\ \text { Business } & 45000 & \text { Monogamous } \\ \text { Business } & 10000 & \text { Monogamous } \\ \text { Civil Servant } & 150000 & \text { Monogamous } \\ \text { Civil Servant } & 41000 & \text { Monogamous } \\ \text { Teacher } & 94000 & \text { Monogamous } \\ \text { Civil servant } & 80000 & \text { Monogamous } \\ \text { Business } & 70000 & \text { Extended } \\ \text { Entrepreneur } & 200000 & \text { Extended }\end{array}$

Monthly Family type

income

(Naira)

Thus, infertility could be self-inflicted or manmade. As inferred from the study, worldliness explains lifestyle choices or habits like waywardness, alcoholism, substance abuse, sexual promiscuity, abortion and the use of contraceptives. These were described by many as the cause of their childlessness.

For example, Lola, who has been married for 10years attributed his condition to "worldliness". He stated that "this delay in childbearing is due to my worldliness. I like to enjoy life and I indulged in heavy smoking, drinking and other toxic substances. It has given me low sperm count..this disorder in my body that I have caused myself". Similarly, Moses, a bittered 50-year-old man who said he could not divorce his wife ascribed his family's childlessness to his wife's worldly actions. He claimed that "My wife that is infertile. I did not know my wife was so loose because we were married in the church... I did not have the chance for worldliness like parties and some other things like her and that has been my nature".

Worldliness: Many of the participants believe that infertility mostly results from one's actions or inactions. 
The study also shows that peer pressure could lure some into actions that could lead to infertility. This perception was reiterated by Seun who is in a polygamous marriage. She stated that "I sometimes blame myself for my past wayward life. To be with friends and be trendy, I have had abortions, used contraceptives and other things that will not allow one to get pregnant. Now I know that shameful pregnancy before marriage is better than infertility later in marriage”.

In the same vein, Shade affirmed that "I am the cause of our childlessness but I cannot bring myself to tell my husband. When I was in secondary school I got pregnant and because I didn't want my parents to know I mixed so many things .....to ensure the pregnancy comes out... I was later told by the doctor that my fallopian tubes are damaged that I may never be able to conceive”.

Rape: Unlike reports from previous studies, some of the participants believed that rape can lead to infertility. \%ัे They claimed that violent rape can destroy the uterus and other vital reproductive organs. Stigmatization of rape victims and the silence that accompanies rape incidents 要 were also held as causal factors. For example, Iyanu related the cause of her infertility to rape. She stated that "when I was in primary school I was raped multiple times by a man who happens to be our neighbor but I was too ashamed to tell anyone....no one suspected anything... I was later diagnosed with pelvic inflammatory disease, which has resulted in the blockage of my fallopian tubes. I always blame myself for not disclosing the incident on time to my parents; maybe I would have been treated and saved my life from this horrible situation".

Modernization: Another peculiar finding is the link between modernization and infertility. Some participants like Tunde believed infertility is associated with the destruction of traditional values and practices and the adoption of Western cultures. He stated that "I blame civilization and Christianity. I just married my wife because she is a Christian. We did not follow the traditional means of ascertaining the type of girl she is or the family she comes from... She might be possessed...I think she could be lying and conniving with the doctor to cover the cause since her father is a nurse".

Spiritual causes of infertility: Spiritual causes of infertility describe participants' perceptions of infertility as resulting from God or supernatural forces. These are often explained as:
Trial: Some participants felt they are victims of infertility, as such, they perceived their conditions as life trials. For instance, Fatima stated "I just believe everything that happens to a man is not without God's knowledge and permission. The common belief is that promiscuous women might be barren either by destroying their wombs through abortion or killing all the children they are destined to have. I married as a virgin and I cannot tell why God has permitted me to be afflicted this way".

Aminat also reiterated this belief by saying "I see myself as a victim of infertility. Married a virgin I would never have thought I could be infertile. I kept myself so much and all to experience this".

Another participant, Tunji, who has infertility for 15 years believed that their condition was God's will since there's no medical explanation for it.

God's punishment: A number of the participants believed their situations were justified because of their "wayward or promiscuous past", hence they are receiving the "right punishment for their deeds". This perception was clearly illustrated by Wale who asserted that "God could have made me infertile because when I was much younger I had girlfriends and two had abortions for me. I believe God is punishing me for those abortions they had. Medically, nothing is wrong with me and I don't think my wife has any issues. I know the reasons are spiritual".

Spiritual oppression: It must be noted that sociobehavioural factors often overlap with spiritual factors. Some participants believed infertility could result from "the wicked". For example, Blessing explained that "the wicked might afflict barrenness on the good ones. According to the gynecologists, they have done everything that is necessary to make sure I get a result but none has succeeded. so, I believe the evil ones are at work. Science has done its part it is now left for God to do his part".

Faith also believed her situation originates from her mother-in-law. She stated that "in my own case my mother-in-law did not want me to marry my husband. I decided to marry him since he is the one I want to marry not his Mom. At a time I started thinking the delay could be from her because she does not like me still. We have tried the medical, the spiritual and I know that at God's appointed time, it will happen." Ola who knew her husband had low sperm count also attributed their 
infertility to "the works of the world and the wicked" since she has done intrauterine insemination (IUI) twice without success. She worries that she might be "spiritually oppressed".

These clearly show that infertility is spiritually perceived to be an 'attack' or 'trial for individuals without sin'. Also, most explanations for unexplained infertility are patterned along supernaturalism. Thus, one can surmise that as demonstrated by several studies $4,11,17,20-22$, the sociocultural perceptions of the cause of infertility are exalted above medical causes which the participants believed are aftermaths of the former.

\section{Conclusion}

In Kwara South, Nigeria, female infertility is defined as the failure of a married woman to achieve a pregnancy that will lead to successful childbirth while male infertility is linked to impotence. Although all the 할 participants acknowledged that infertility could result from sexually transmitted infections (STIs) and other bodily disorders, they altogether believed that these results from lifestyle choices and could be linked to the supernatural. Thus, perceptions of the cause of infertility are rooted in the general Nigerian culture. This study has further established that culture and spirituality play a major role in people's perceptions and explanations of infertility across nations. There is a need to renegotiate these sociocultural perceptions and integrate them into preventive and curative strategies aimed at improving seproductive healthcare in Nigeria.

\section{Conflict of Interest: Nil}

\section{Source of Funding: Self}

\section{Ethical Clearance: Department Committee}

\section{References}

1. Van Balen F, Inhorn M. Interpreting infertility, a view from the social science. Interpreting infertility: childlessness, gender and reproductive technologies in global prospective UCLA Press, Berkley. 2002.

2. Perslev K, Msemo O, Minja D, Møller S, Theander T, Lusingu J, et al. Marked reduction in fertility among African women with urogenital infections: A prospective cohort study. PloS one. 2019;14(1):e0210421.
3. Inhorn MC, Patrizio P. Infertility around the globe: new thinking on gender, reproductive technologies and global movements in the 21st century. Human reproduction update. 2015;21(4):411-26.

4. Okonofua FE. Female and male infertility in Nigeria. From Dept Public Health Sciences, Karolinska Institutet, Stockholm, Sweden. 2005:68.

5. Panti AA, Sununu YT. The profile of infertility in a teaching Hospital in North West Nigeria. Sahel Medical Journal. 2014;17(1):7.

6. Okonofua FE, Harris D, Odebiyi A, Kane T, Snow RC. The social meaning of infertility in Southwest Nigeria. 1997.

7. Ombelet W. False perceptions and common misunderstandings surrounding the subject of infertility in developing countries. ESHRE Monographs. 2008;2008(1):8-11.

8. Geelhoed D, Nayembil D, Asare K, Schagen van Leeuwen J, Van Roosmalen J. Infertility in rural Ghana. International Journal of Gynecology \& Obstetrics. 2002;79(2):137-42.

9. Henshaw SK, Singh S, Haas T. The incidence of abortion worldwide. International family planning perspectives. 1999:S30-S8.

10. Grimes DA, Benson J, Singh S, Romero M, Ganatra B, Okonofua FE, et al. Unsafe abortion: the preventable pandemic. The lancet. 2006;368(9550):1908-19.

11. Tabong PT-N, Adongo PB. Understanding the social meaning of infertility and childbearing: a qualitative study of the perception of childbearing and childlessness in Northern Ghana. PloS one. 2013;8(1):e54429.

12. Deribe K, Anberbir A, Regassa G, Belachew T, Biadgilign S. Infertility: Perceived Causes and Experiences in Rural Southwest Ethiopia. Age $(\mathrm{N}=$ 223*). 2007;20(2):0.9.

13. Pearce TO. She Will Not Be Listened to in Public: Perceptions Among the Yoruba of Infertility and Childlessness in Women. Reproductive Health Matters. 1999;7(13):69-79.

14. Olu Pearce T. She will not be listened to in public: Perceptions among the Yoruba of infertility and childlessness in women. Reproductive Health Matters. 1999;7(13):69-79.

15. Lincoln YS, Guba EG. Naturalistic inquiry. Newberry Park. CA: Sage; 1985. 
16. Upkong D, Orji E. Mental health of infertile women in Nigeria. Turk psikiyatri dergisi= Turkish journal of psychiatry. 2006;17(4):259.

17. Sala Uddin G, Haque A, Nejum MdR WI. Current Consequence and Research of Human Infertility in Bangladesh. J Reproductive Endocrinol \& Infert. 2018;3(1):4.

18. Koster-Oyekan W. Infertility among Yoruba women: Perceptions on causes, treatments and consequences. African Journal of Reproductive Health. 1999;3(1):13-26.

19. Sarkar S, Gupta P. Socio-Demographic Correlates of Women's Infertility and Treatment Seeking Behavior in India. Journal of reproduction \& infertility. 2016;17(2):123-32.
20. Araoye MO. Epidemiology of infertility: social problems of the infertile couples. West African journal of medicine. 2003;22(2):190-6.

21. Ali S, Sophie R, Imam AM, Khan FI, Ali SF, Shaikh A, et al. Knowledge, perceptions and myths regarding infertility among selected adult population in Pakistan: a cross-sectional study. BMC Public Health. 2011;11(1):760.

22. Greil A, McQuillan J, Slauson-Blevins K. The Social Construction of Infertility. Sociology Compass. 2011;5(8):736-46. 